LA-14257-M

Manual

Approved for public release;

distribution is unlimited.

Manual for the

Portable Handheld Neutron Counter (PHNC)

for Neutron Survey and the Measurement

of Plutonium Samples 
Los Alamos National Laboratory, an affirmative action/equal opportunity employer, is operated by the University of California for the United States Department of Energy under contract W-7405-ENG-36.

This report was prepared as an account of work sponsored by an agency of the United States Government. Neither the Regents of the University of California, the United States Government nor any agency thereof, nor any of their employees make any warranty, express or implied, or assume any legal liability or responsibility for the accuracy, completeness, or usefulness of any information, apparatus, product, or process disclosed, or represent that its use would not infringe privately owned rights. Reference herein to any specific commercial product, process, or service by trade name, trademark, manufacturer, or otherwise does not necessarily constitute or imply its endorsement, recommendation, or favoring by the Regents of the University of California, the United States Government, or any agency thereof. The views and opinions of authors expressed herein do not necessarily state or reflect those of the Regents of the University of California, the United States Government, or any agency thereof. Los Alamos National Laboratory strongly supports academic freedom and a researcher's right to publish; as an institution, however, the Laboratory does not endorse the viewpoint of a publication or guarantee its technical correctness. 
LA-14257-M

Manual

Issued: November 2005

\section{Manual for the \\ Portable Handheld Neutron Counter (PHNC) \\ for Neutron Survey and the Measurement \\ of Plutonium Samples}

H. O. Menlove 



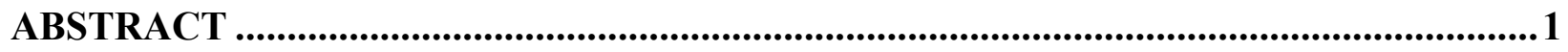

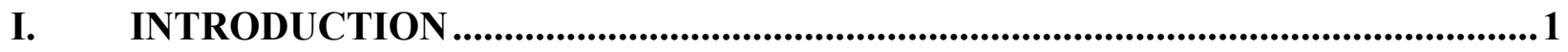

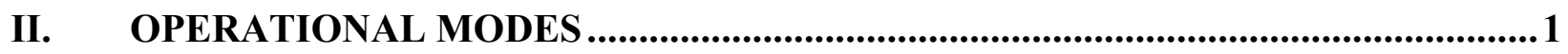

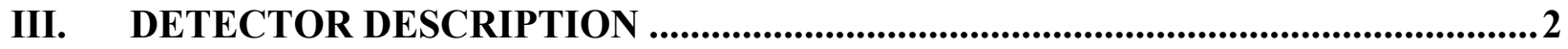

A. Neutron Detector ...........................................................................................................2

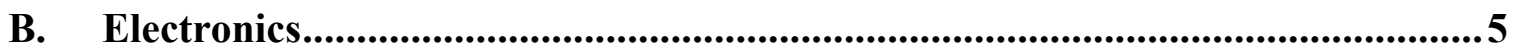

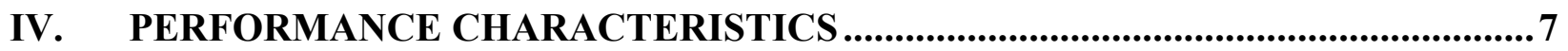

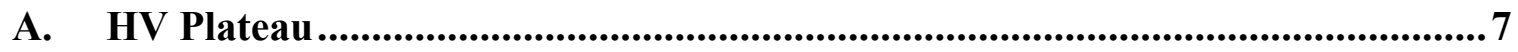

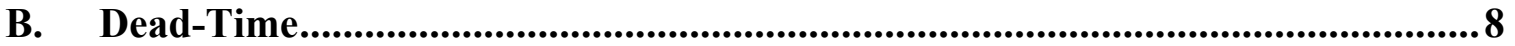

C Die-Away Time .........................................................................................................10

D. Gate Length .............................................................................................................11

E. Efficiency..............................................................................................................12

F. Efficiency Profiles ....................................................................................................13

G. Stability and Moisture Sensitivity ......................................................................15

H. Vibration Tests ........................................................................................................ 15

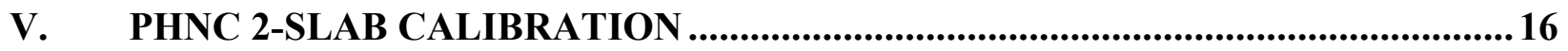

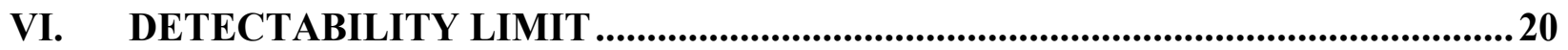

A. Room Background ....................................................................................................20

B. Lower Limit of Detection LLD..............................................................................21

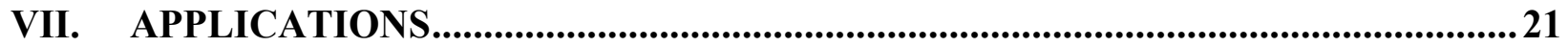

A. Wide-Area Search Mode .....................................................................................21

B. Quantitative Coincidence Mode....................................................................................23

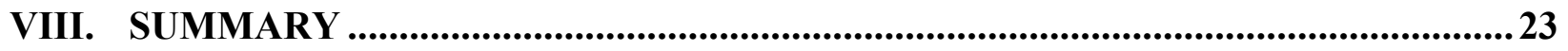

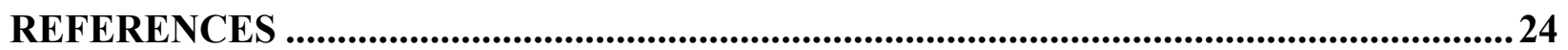




\title{
MANUAL FOR THE PORTABLE HANDHELD NEUTRON COUNTER (PHNC) FOR NEUTRON SURVEY AND THE MEASUREMENT OF PLUTONIUM SAMPLES
}

\author{
by
}

\author{
H. O. Menlove
}

\begin{abstract}
We have designed a portable neutron detector for passive neutron scanning measurement and coincidence counting of bulk samples of plutonium. The counter will be used for neutron survey applications as well as the measurement of plutonium samples for portable applications. The detector uses advanced design ${ }^{3} \mathrm{He}$ tubes to increase the efficiency and battery operated shift register electronics. This report describes the hardware, performance, and calibration for the system.
\end{abstract}

\section{INTRODUCTION}

Neutron detectors using ${ }^{3} \mathrm{He}$ tubes have been used extensively for quantitative measurements of uranium and plutonium for safeguards and nuclear material accountability [1]. The measurements are normally made using neutron time-correlation (coincidence) counting or multiplicity counting to obtain the plutonium or uranium mass. The Portable Handheld Neutron Counter (PHNC) has been developed to support ad hoc field inspections requiring performance under non-laboratory conditions. The system is configured to operate in the totals mode for area scanning or in the coincidence mode for quantitative assay.

The hardware, performance measurements, and initial calibration of the PHNC are described in this manual.

\section{OPERATIONAL MODES}

The PHNC can be operated in multiple modes. Large-area surveys can be accomplished by counting singles, with the detectors remaining in the carrying case or positioned in such a manner as to provide directional sensitivity. Coincidence counting can provide verification measurement capability through field configuration of the pair of ${ }^{3} \mathrm{He}$ detector slabs or, for larger samples, multiple slab pairs, in a geometry with relatively high counting efficiency. For the field survey mode, the detectors remain inside the carrying case, and the electronics control module is attached to the outside of the case. A GPS can be added to the system to provide position information. Data interpretation is aided by the use of a detailed MCNPX [2] model, which enables normalization of the arbitrary configurations used in the field to a standard that has been calibrated. 


\section{DETECTOR DESCRIPTION}

\section{A. Neutron Detector}

Each of the detector heads consists of four He-3 tubes with active lengths of $17.8 \mathrm{~cm}$ that are embedded in high-density polyethylene (HDPE), as shown in Fig.1. The detector module has been produced for commercial sale by PDT Corporation [3] and is available as model PDT 20ALANL1. Figure 2 shows the dimensions of the detector, which has a weight of $3.8 \mathrm{~kg}$. A new method of embedding the He-3 tubes into the high voltage (HV) and amplifier package was developed by PDT to reduce the size and weight of the unit. A single-detector module is shown in Fig. 3. The slab can be carried using the shoulder strap, but the electronics package would need to be carried with a belt strap.

For coincidence applications, two of the detector slabs are connected, as shown in Fig. 4, with HDPE side pieces to fix the geometry and increase the efficiency. The sample cavity size is $112 \times 127 \mathrm{~mm}$ in this configuration. Figure 5 shows the front side open to show the HDPE piece for the front side. There are three HDPE pieces that are used for the coincidence geometry with the two side brackets and the 2.54-cm-thick HDPE bottom plate to isolate the counting efficiency from the table or floor material. Without the HDPE isolation plate, the efficiency changes with different surface materials.

To determine the thickness of HDPE for the bottom plate to isolate the measurement from the tabletop material, a series of measurements were performed with a Cf- 252 source in the center of the sample cavity and different thicknesses of HDPE under the counter. The results are shown in Fig. 6, where we see that $2.54 \mathrm{~cm}$ of HDPE gives adequate isolation.

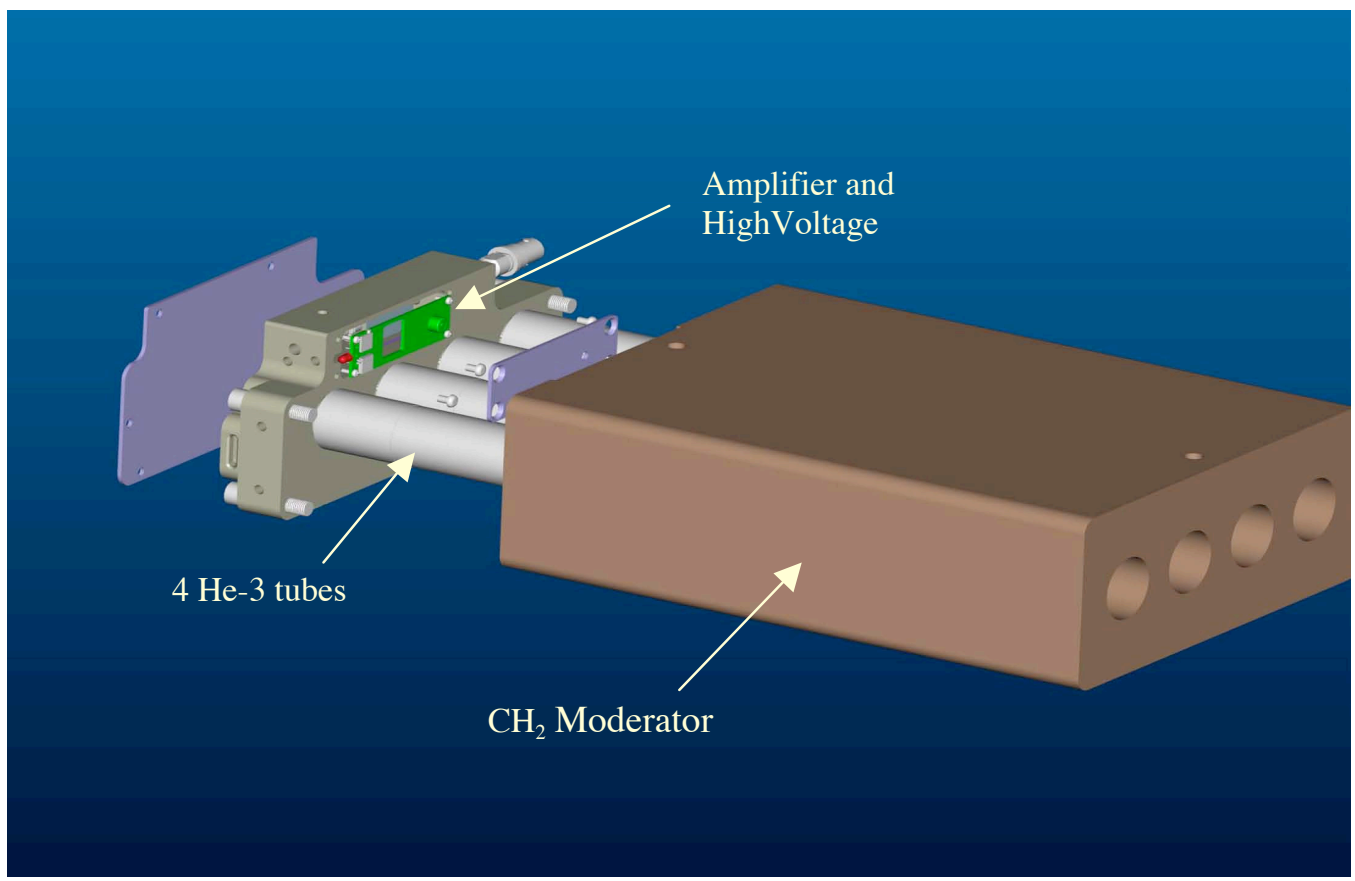

Fig. 1. Diagram of the PHNC, showing the layout of the ${ }^{3}$ He tubes in the HDPE detector body. 

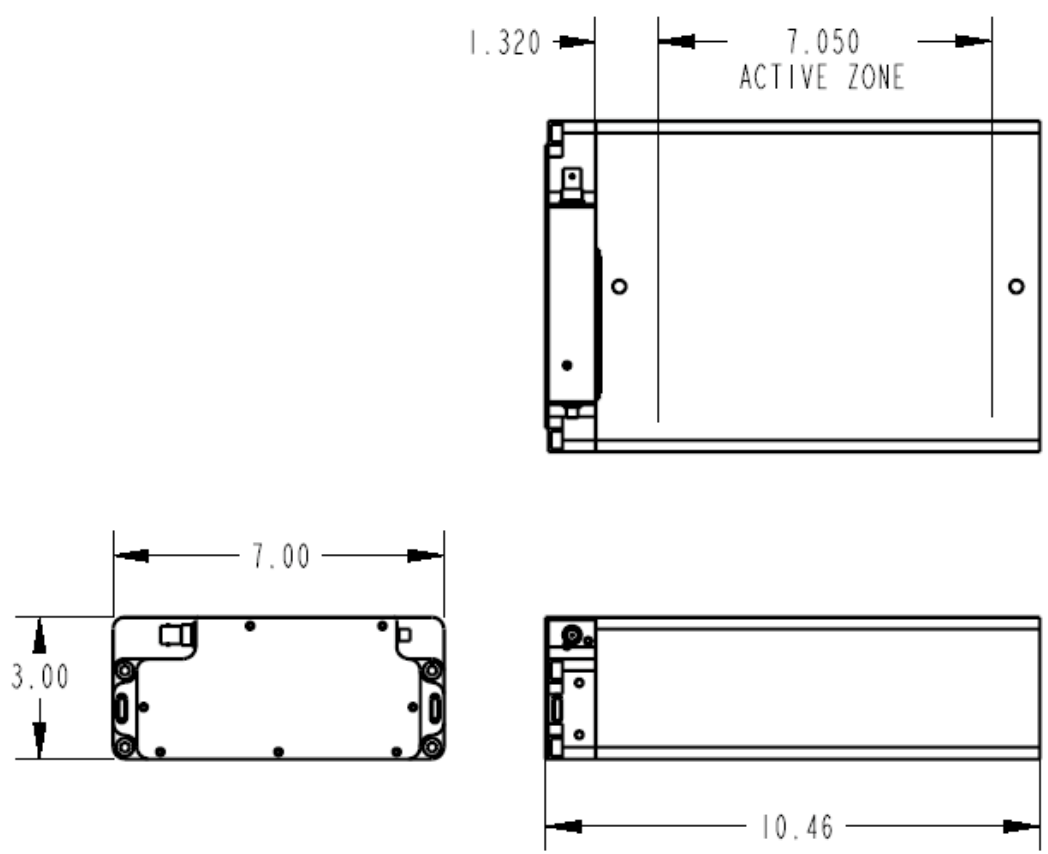

Fig. 2. Drawing dimensions in inches for the PHNC.

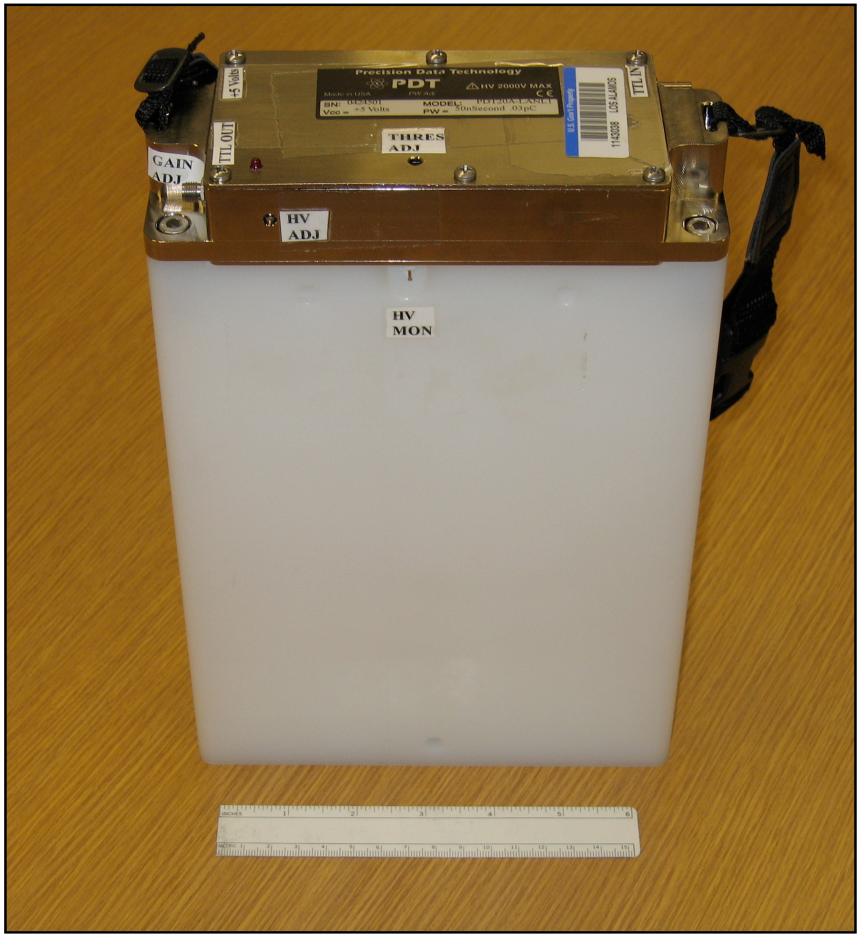

Fig. 3. Photograph of the PHNC with a single unit to be carried by the shoulder strap. 


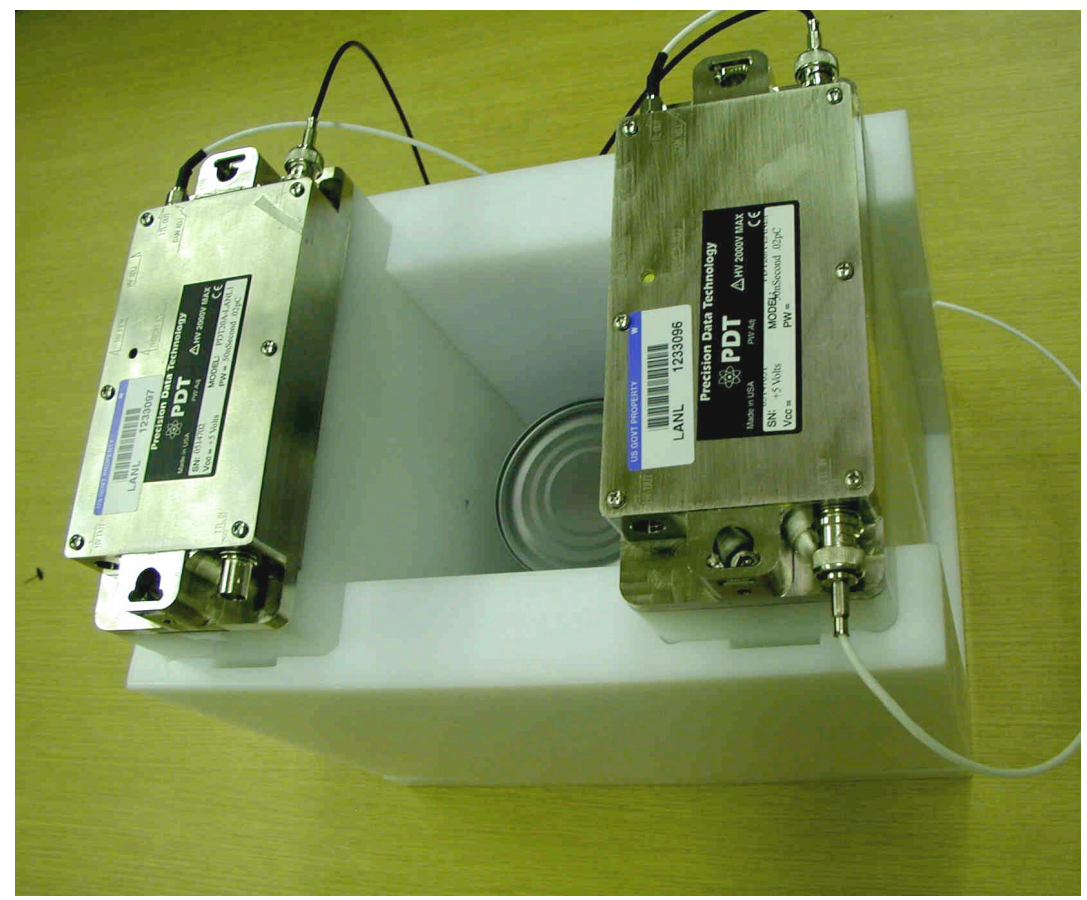

Fig. 4. For neutron coincidence counting, the two slabs can be connected with side brackets to fix the geometry for quantitative assay.



Fig. 5. Two PHNC detector slabs, with the HDPE side opened to show the sample cavity. 


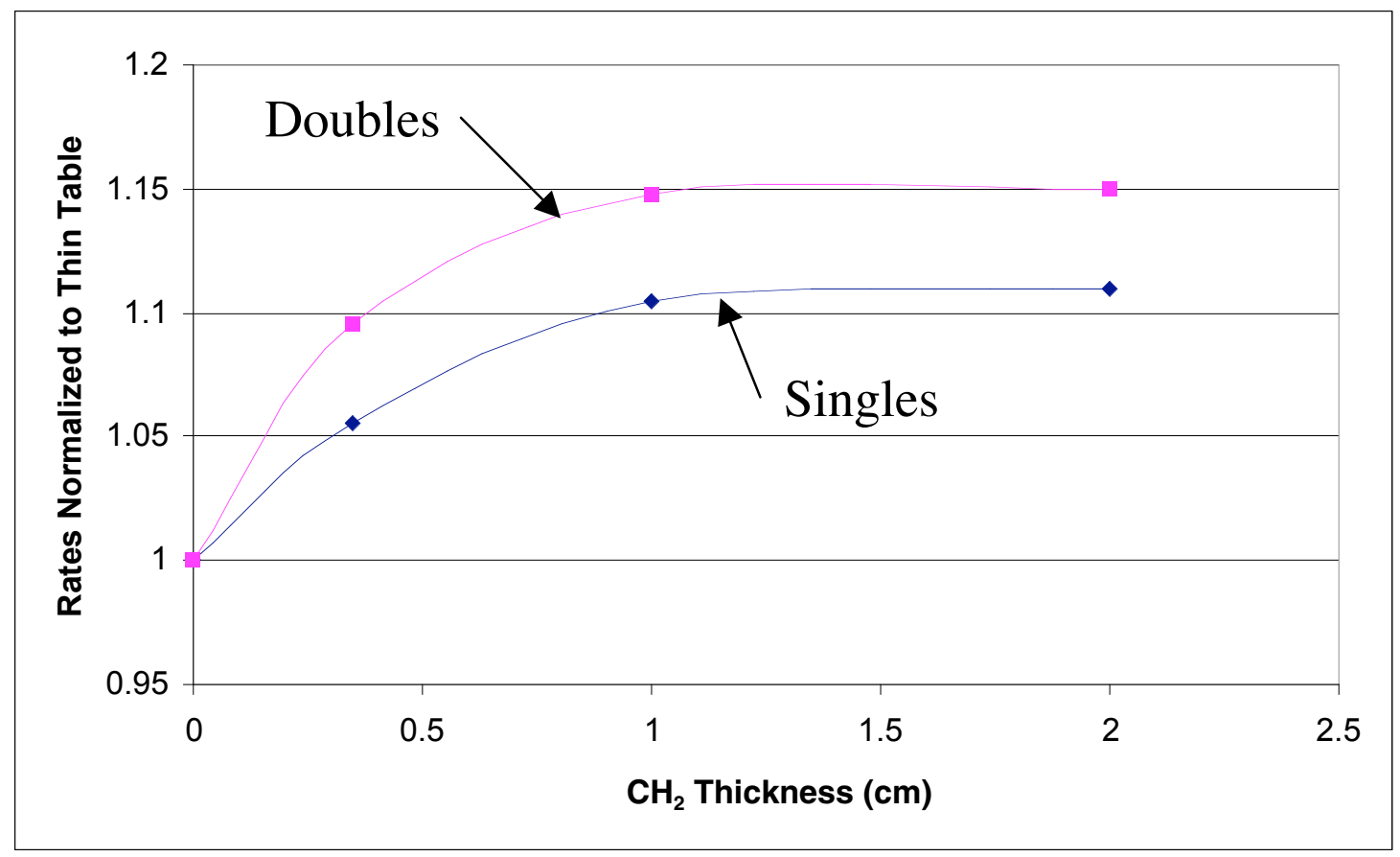

Fig. 6. Detector efficiency versus thickness of the HDPE bottom plate for isolation from the table material.

\section{B. Electronics}

The PHNC detector modules are available from PDT Corporation. The PHNC amplifier is based on the original PDT-20A. The HV supply is internal to the unit as shown in Fig. 1. The $\mathrm{HV}$ is generated from the low voltage $+5 \mathrm{~V}$ that is supplied from the electronics control package. The adjustment parameters in the PHNC are the HV, gain, and the discriminator level.

The PHNC can be operated in the singles mode for wide-area scanning or in the coincidence mode for quantitative assay. Two different electronic modules that are battery powered have been developed to supply the low voltage power and collect the data. The first unit, called the Dual-Channel Counter [4], supplies two low voltage power outputs, two HV outputs (not used for PHNC), two scalars, and a timer. The electronics module, together with two detector slabs, is shown in Fig. 7, where the system is in a briefcase for transport.

For battery powered coincidence or multiplicity mode operation, the new hand-held multiplicity shift register (HHMR) [5] can be used. This unit is shown in Fig. 8. Both of the electronic units have an RS232 interface with a minicomputer for data collection and analysis. 


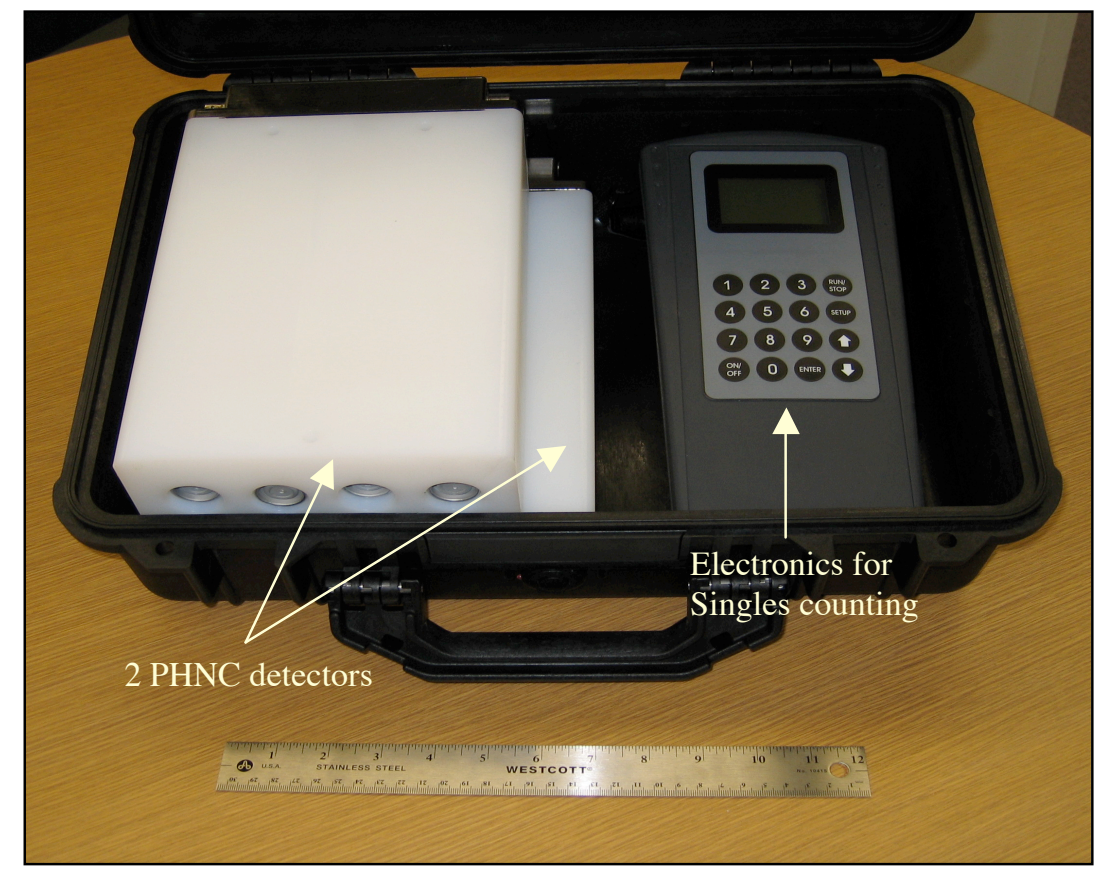

Fig. 7. The Dual Channel Counter singles mode electronics and a pair of PHNC slabs in a carrying case.

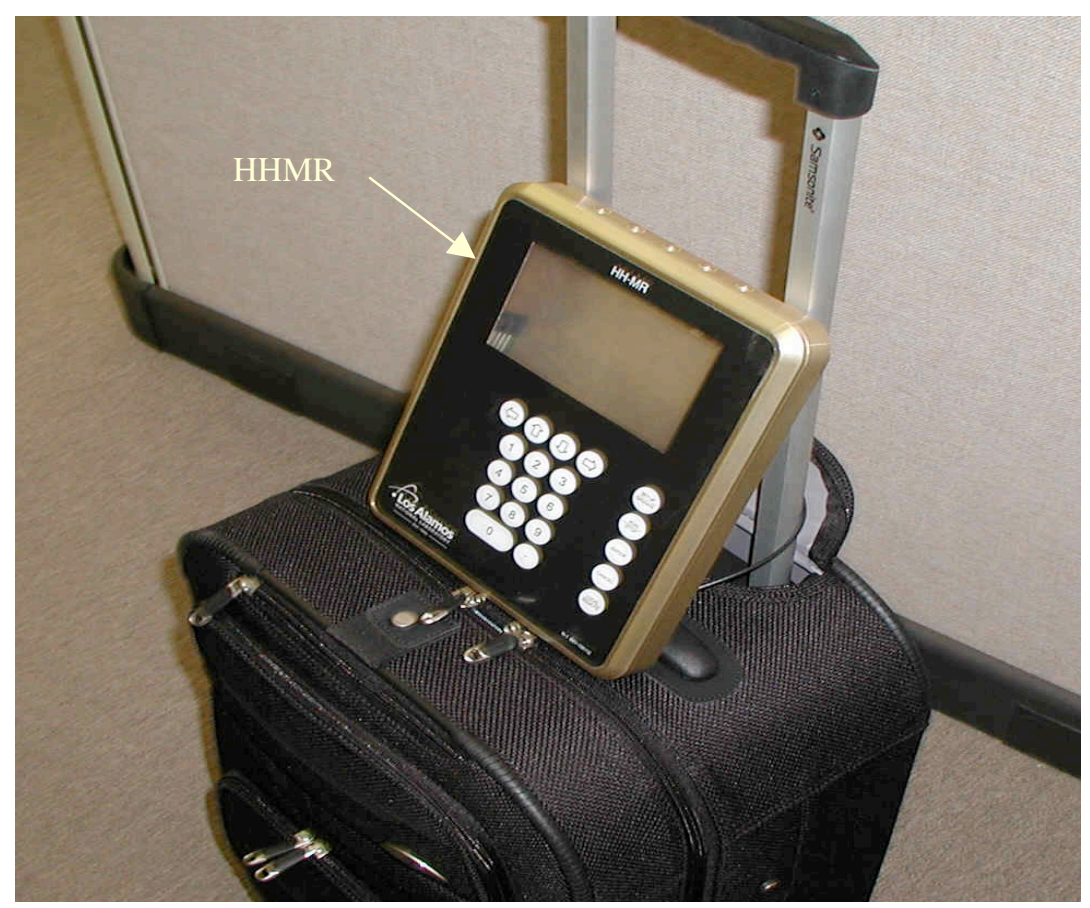

Fig. 8. The HHMR electronics for coincidence mode quantitative measurements. 


\section{PERFORMANCE CHARACTERISTICS}

\section{A. HV Plateau}

A series of measurements were made using ${ }^{252} \mathrm{Cf}$ and plutonium to characterize the detector. The detector bias plateau is shown in Fig. 9. Because the HV is generated internal to the PHNC, there is no requirement to match all PHNC units to operate at the same HV. However, it is necessary for all of the PHNC units to have the same efficiency so that the units can be used interchangeably. The gains in all of the amplifiers have been matched so that the counting rate from a single unit is the same as for the other six units.



Fig 9. The plateau curves for a single PHNC amplifier that is typical.

The Cf-252 source (Cf-9) was placed on the center of the face of the PHNC, and the gains were adjusted so that the operating HV was $40 \mathrm{~V}$ above the "knee" of the plateau curve. Table I gives the results of the PHNC efficiency matching for each of the PHNC units. The average variation in the efficiency of the 7 units is less than $1 \%$. The design of the PHNC is symmetric so that the efficiencies of the front and back faces are the same. However, if two slabs are placed back-to-back, the ratio of the rates in two slabs provides directional information.

Table I presents the detector serial numbers and the counting rates for a californium source (Cf-9 on 7/26/05) attached to the center of the face of the PHNC. The doubles gate was $64 \mu$ s for the tests, and this was changed later to $128 \mu \mathrm{s}$ to optimize the precision and dead-time. The ratio of the doubles at $128 \mu$ s over $64 \mu$ s is 1.316 . 


\begin{tabular}{|c|c|c|c|c|c|}
\hline \multicolumn{6}{|c|}{ TABLE I. PHNC Identification and Efficiency Matching } \\
\hline Property No. & Serial No. & $\begin{array}{c}\text { HV } \\
\text { (fixed) }\end{array}$ & $\begin{array}{c}\text { Singles } \\
\text { (CF-9) }\end{array}$ & $\begin{array}{c}\text { Doubles } \\
\text { (Cf-9) }\end{array}$ & $\begin{array}{c}\text { Doubles } \\
\text { sigma }\end{array}$ \\
\hline 1143038 & 0424501 & $\sim 1680^{*}$ & $(3186)^{*}$ & N/A & N/A \\
\hline 1143037 & 0424502 & 1680 & 3133 & 178 & 2.4 \\
\hline 1232905 & 0501501 & 1740 & 3167 & 181 & 2.8 \\
\hline 1232906 & 0501502 & 1678 & 3128 & 182 & 0.4 \\
\hline 1233096 & $(0501501)$ & 1700 & 3176 & 188 & 2.2 \\
\hline 1233097 & 0514702 & 1726 & 3151 & 186 & 2.5 \\
\hline 1233518 & 0514703 & 1740 & 3149 & 187 & 2.5 \\
\hline 1233519 & 0514704 & 1740 & 3139 & 182 & 2.2 \\
\hline & & & $\begin{array}{c}\text { Ave }=3149 \\
\text { RSD }=0.54 \%\end{array}$ & \\
\hline
\end{tabular}

* The first PHNC unit was sent to TRP for field tests prior to the calibration measurements.

\section{B. Dead-Time}

The dead-time coefficients were measured using pairs of ${ }^{252} \mathrm{Cf}$ sources with known yields and a large difference between their yields. Table II lists sources for which the ratios of the source yields are known. The A and B coefficients were determined using the known source ratios. For the present case, with only two amplifiers, the dead-time is large and the ratio of $\mathrm{A} / \mathrm{B}$ was fixed at 3.1, based on prior work.

The dead-time equations for corrected rates for the singles and doubles are given by

$$
S(\text { corr })=S(\text { meas }) e^{\frac{\delta S}{4}}
$$

and

$$
D(\text { corr })=D(\text { meas }) e^{\delta S}
$$

where

$$
\delta=\left(a+b \bullet S \bullet 10^{-6}\right) \mu \mathrm{s}
$$

and the dead-time parameter $b=a / 3.1$. 


\begin{tabular}{|c|c|c|c|c|c|c|}
\hline TABLE II. Cf-252 Sources Used for Dead-Time Calculation \\
\hline & $\begin{array}{c}\text { S } \\
\text { Source }\end{array}$ & Ratio & A & B & Multiplicity & $\begin{array}{c}\text { Multiplicity } \\
\text { C }\end{array}$ \\
\hline Cf-12/Cf-6 & 82110 & 56.50 & 4.251 & 1.371 & 1000 & N/A \\
\hline Cf-12/Cf-3 & 82110 & 402.6 & 4.311 & 1.391 & 1000 & N/A \\
\hline Cf-10/Cf-3 & 24591 & 112.5 & 4.288 & 1.383 & 1000 & N/A \\
\hline Weighted Average & N/A & N/A & 4.283 & 1.382 & 1000 & 11.3 \\
\hline
\end{tabular}

We see that the dead-time coefficients are roughly a factor of 2 higher for the present PDT-10A type amplifiers than for the faster AMPEK A111 type amplifiers. The counting rates anticipated in the PHNC are low, and the higher dead-time should not be important.

Note in Table III, that the multiplicity dead-time coefficient is set at the maximum value of 1000. This is the limit set in the INCC software for a gate of $128 \mu$ s because of calculational constraints. To obtain an accurate dead-time correction, it was necessary to increase the correction for the triples rate by the $\mathrm{C}$ factor in the INCC software [6]. The triples rate has a relatively large dead-time correction, and the large coefficient is required to make use of the multiplicity capability in the PHNC.

To test the accuracy of the dead-time coefficients, we applied the correction to the triples and doubles rates over a wide range of source yields. The ratio of T/D should remain constant if the dead-time correction is accurate. Figure 10 shows a plot of the T/D ratio for rates up to 90,000 cps. This ratio should be constant for the correct dead-time parameters.

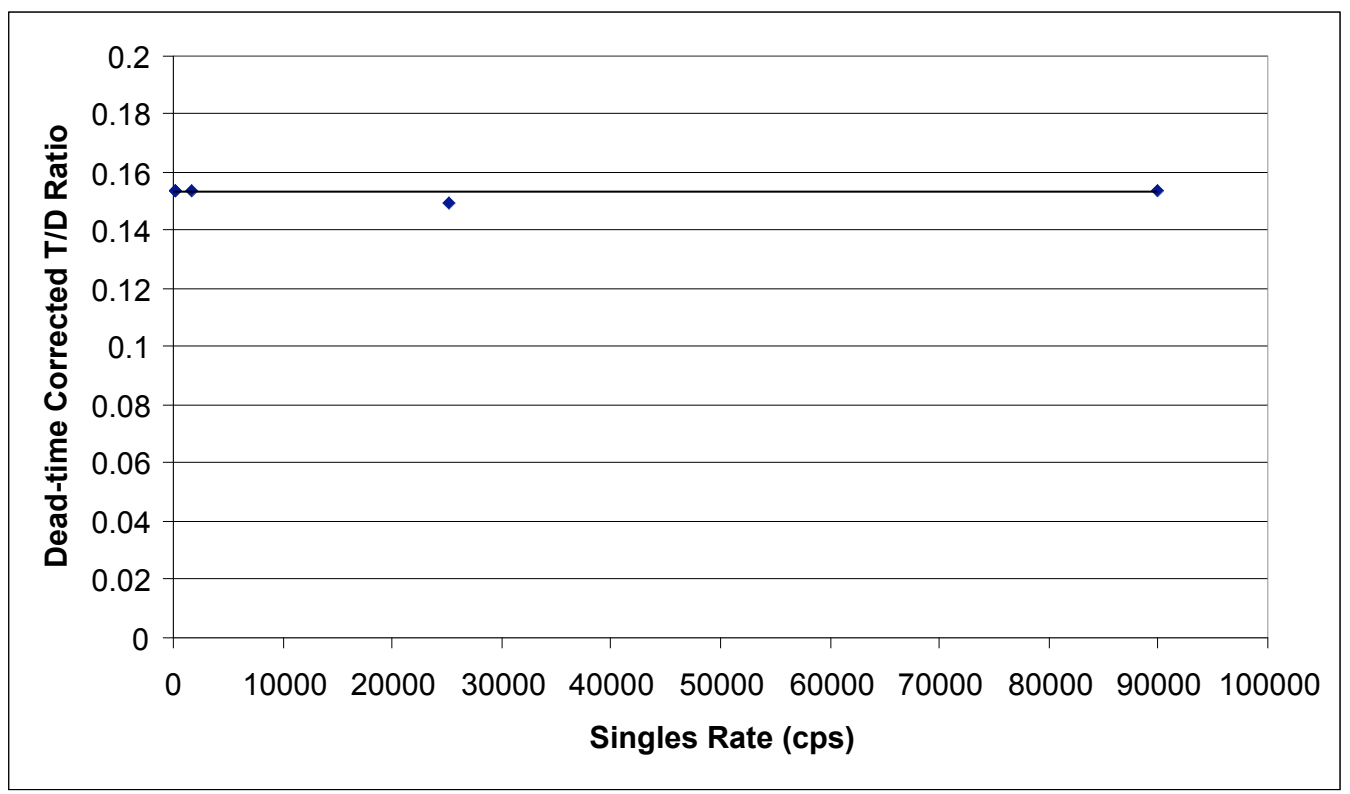

Fig. 10. Dead-time corrected T/D ratio as a function of counting rate. The ratio was constant up to 90,000 cps. 
The dead-time coefficients are listed in Table III.

\begin{tabular}{|l|l|}
\hline \multicolumn{1}{|c|}{ TABLE III. PHNC Performance Parameters } \\
\hline \hline \multicolumn{1}{|c|}{ Parameter } & \multicolumn{1}{|c|}{ Value } \\
\hline $\begin{array}{l}\text { PHNC intrinsic efficiency for 1 slab per } \\
\text { incident neutron ( }{ }^{240} \mathrm{Pu} \text { energy) }\end{array}$ & $13.3 \%$ \\
\hline PHNC efficiency for 2-slabs ( ${ }^{240} \mathrm{Pu}$ energy) & $7.4 \%$ \\
\hline Die-away time (ENMC) & $\sim 85 \mu \mathrm{s}$ \\
\hline Operating bias (different for each unit) & $\sim 1700 \mathrm{~V}$ \\
\hline Dead-time coefficients & \\
\hline A & 4.283 \\
\hline B (A/20) & 1.382 \\
\hline C & 11.3 \\
\hline Multiplicity dead time & $1000 \mathrm{~ns}$ \\
\hline Gate & $128 \mu \mathrm{s}$ \\
\hline Predelay & $3.0 \mu \mathrm{s}$ \\
\hline Doubles gate fraction & 0.673 \\
\hline Triples gate fraction & 0.453 \\
\hline$\rho_{0}$ constant & 0.0523 \\
\hline
\end{tabular}

\section{Die-Away Time}

The neutron die-away time was measured using gate settings from 16 to $200 \mu$ s. The data are shown in Table IV. The measured die-away time was $\sim 85 \mu \mathrm{s}$ for the time region that brackets the gate setting of $128 \mu \mathrm{s}$. There is more than one neutron decay constant, and longer die-away times are observed at longer gate settings. The absence of cadmium absorbers on the walls of the PHNC and the large amounts of HDPE in the two slab configuration result in the relatively large die-away times and the multiple values that increase as the gate interval increases, as shown in Fig. 11. We plan to operate the system at a gate of $128 \mu$ s to obtain the minimum error for design basis sample, and the large multiplicity dead-time correction (>1000 ns) requires a gate of $128 \mu$ s or longer.

\begin{tabular}{|c|c|c|c|c|}
\hline \multicolumn{5}{|c|}{ TABLE IV. Die-Away Time Measurements } \\
\hline $\begin{array}{c}\text { Gate Width } \\
\boldsymbol{\mu s}\end{array}$ & Singles & Doubles & Doubles $\boldsymbol{\sigma}$ & Die-Away Time \\
\hline 16 & 4503 & 126.5 & 0.741 & N/A \\
\hline 32 & 4490 & 205.1 & 1.29 & 31.2 \\
\hline 64 & 4498 & 300.4 & 0.99 & 51.7 \\
\hline 128 & 4498 & 383.6 & 2.69 & 84.7 \\
\hline 200 & 4500 & 420.0 & 2.17 & 118.8 \\
\hline 100 & 4504 & 358.6 & 1.12 & 70.8 \\
\hline 50 & 4506 & 267.3 & 1.71 & 43.1 \\
\hline 25 & 4509 & 175.7 & 0.68 & N/A \\
\hline
\end{tabular}




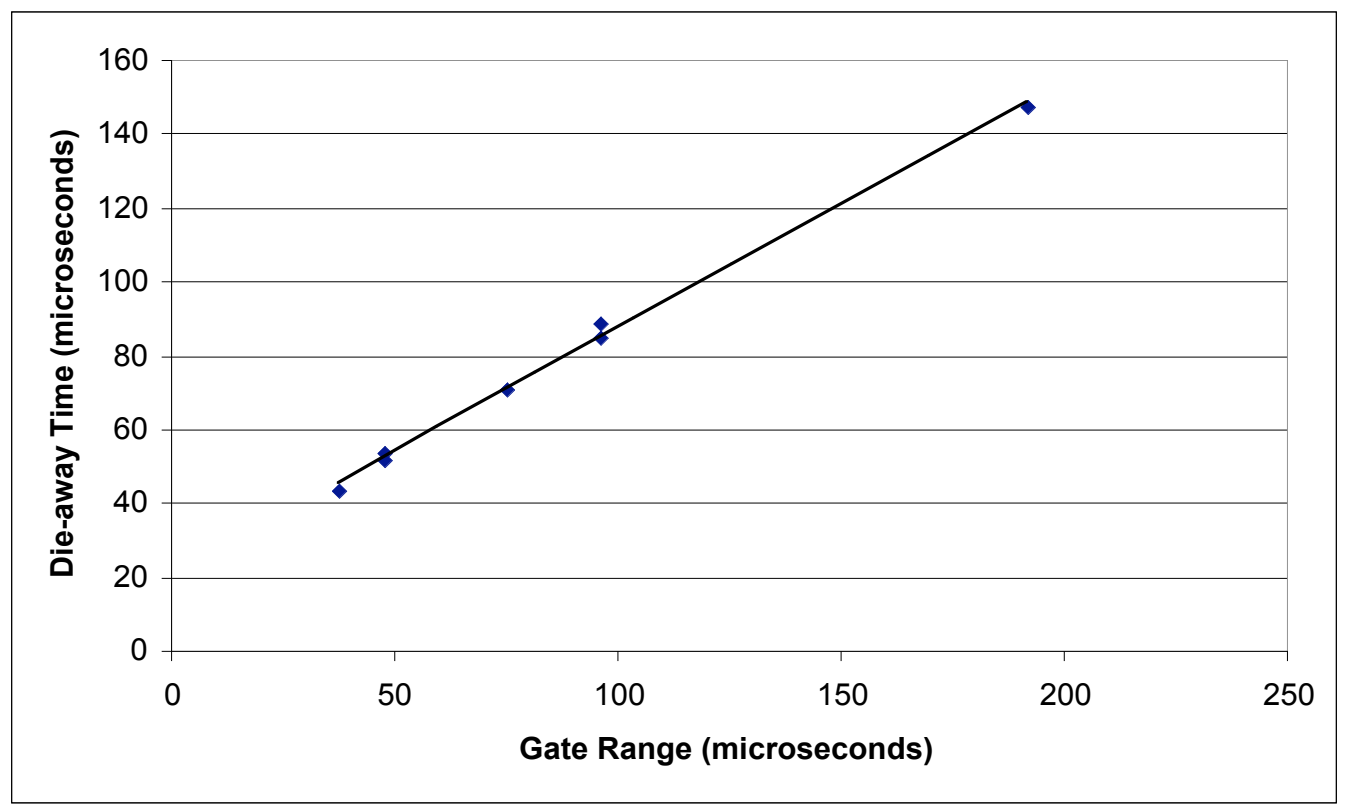

Fig. 11. Die-away time as a function of gate selection for the PHNC in 2-slab geometry.

The multiplicity analysis does not use the $\rho_{0}$ constant; however, the "known alpha" method does. The known alpha method would be used for samples that are pure so that alpha can be calculated from the plutonium isotopics. For low mass samples, the uncorrected doubles rate can be used for the measurement of the plutonium.

\section{Gate Length}

In the past, most neutron coincidence counters used for International Atomic Energy Agency (IAEA) inspection have operated with a predelay gate of $4.5 \mu \mathrm{s}$, and multiplicity counters have used $3.0 \mu \mathrm{s}$. We are using the $3.0 \mu \mathrm{s}$ pre-delay for the PHNC to obtain better counting statistics for the doubles and triples rates. There is a $\sim 20 \%$ savings in the triples measurement time when using the shorter predelay.

To investigate the optimum gate setting for doubles counting, we measured a small Cf-252 source for a fixed counting time $(600 \times 10 \mathrm{~s})$, using gate settings from 16 to $256 \mu \mathrm{s}$. The measured relative statistical error on the doubles rate is shown in Fig. 12. We see that the minimum error is between a 100 and $150 \mu$ s gate setting. The minimum error in the doubles is a function of the singles rate, and we used a source that gave a rate similar to $200 \mathrm{~g}$ of low burnup plutonium oxide. A smaller sample would have a minimum statistical error at longer gates. 


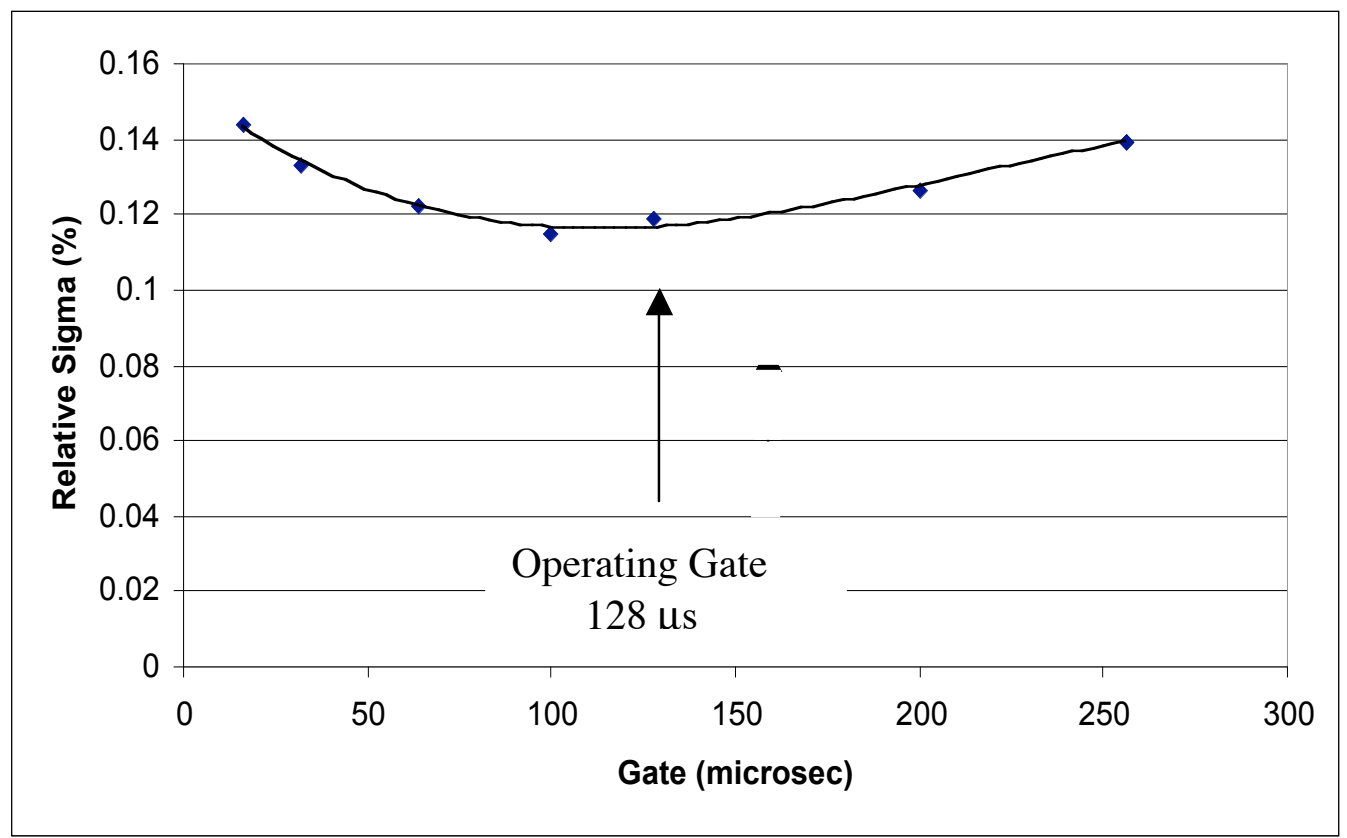

Fig. 12. Statistical error as a function of gate setting for a small Cf-252 sample.

\section{E. Efficiency}

We measured the efficiency of the PHNC using a calibrated ${ }^{252} \mathrm{Cf}$ source, CF-9. The efficiency is a function of the PHNC configuration and the source energy. The efficiency categories are listed below:

1. Intrinsic efficiency $\mathrm{Ei}=$ The fraction of neutrons counted for an incoming beam orthogonal to the face of the HDPE.

2. 2-slab geometry for internal sample $\mathrm{E} 2=$ The fraction of neutrons counted from a sample in the center of the 2-slab geometry shown in Fig. 4.

3. 4-slab geometry for an internal sample $\mathrm{E} 4=$ The fraction of neutrons counted from the center of a 4-slab geometry, with the slabs configured to be touching each other at the corners (178mm square opening).

The efficiencies were measured using $\mathrm{Cf}-252$ sources and plutonium sources in the different geometries. The results of the measurements are given in Table V. Because the PHNC detectors are under-moderated to keep the weight low, the Pu-240 neutrons count more efficiently than the higher energy Cf- 252 neutrons by $\sim 5 \%$. 


\begin{tabular}{|c|c|c|}
\hline \multicolumn{2}{|c|}{ Table V. PHNC Efficiency Measurements } \\
\hline $\begin{array}{c}\text { Detector Efficiency } \\
\text { Configuration }\end{array}$ & Cf-252 Efficiency & Pu-240 Efficiency \\
\hline Ei (face) & $12.7 \%$ & $13.3 \%$ \\
\hline E2 (center) & $7.54 \%$ & $7.9 \%$ \\
\hline E2 (FCZ-158 sample) & N/A & $7.4 \%$ \\
\hline E4 (center) & $\sim 8.0 \%$ & $\sim 8.4 \%$ \\
\hline
\end{tabular}

For the conventional two-parameter analysis of neutron coincidence data, it is useful to define the multiplication constant $\rho_{0}$, where

$$
\rho_{0}=\frac{R}{T}(1+\alpha) \text { (for a nonmultiplying sample), }
$$

where rho-naught is the calculated ratio of alpha-particle-induced neutrons to spontaneousfission neutrons.

A small $0.704 \mathrm{~g}$ enriched ${ }^{240} \mathrm{Pu}$ sample was used to measure $\rho_{0}$, giving 0.0523 , for a predelay of $3.0 \mu \mathrm{s}$ and a gate length of $128 \mu \mathrm{s}$.

\section{F. Efficiency Profiles}

The PHNC has large openings at the top and bottom, and this results in a non-uniform response, as a function of the sample height in the counter. The efficiency profile for the PHNC is shown in Fig.13 for the vertical direction and Fig.14 for the detector face direction. The response in the direction parallel to the face of the slabs is very flat, as shown in Fig. 15 because of the reflection and moderator boost to the sides of the PHNC slabs.

To position the sample in the flat efficiency-counting region, the base of the sample should be approximately $8-10 \mathrm{~cm}$ above the bottom HDPE plate. The sample material should be centered in the vertical and radial directions when possible. 


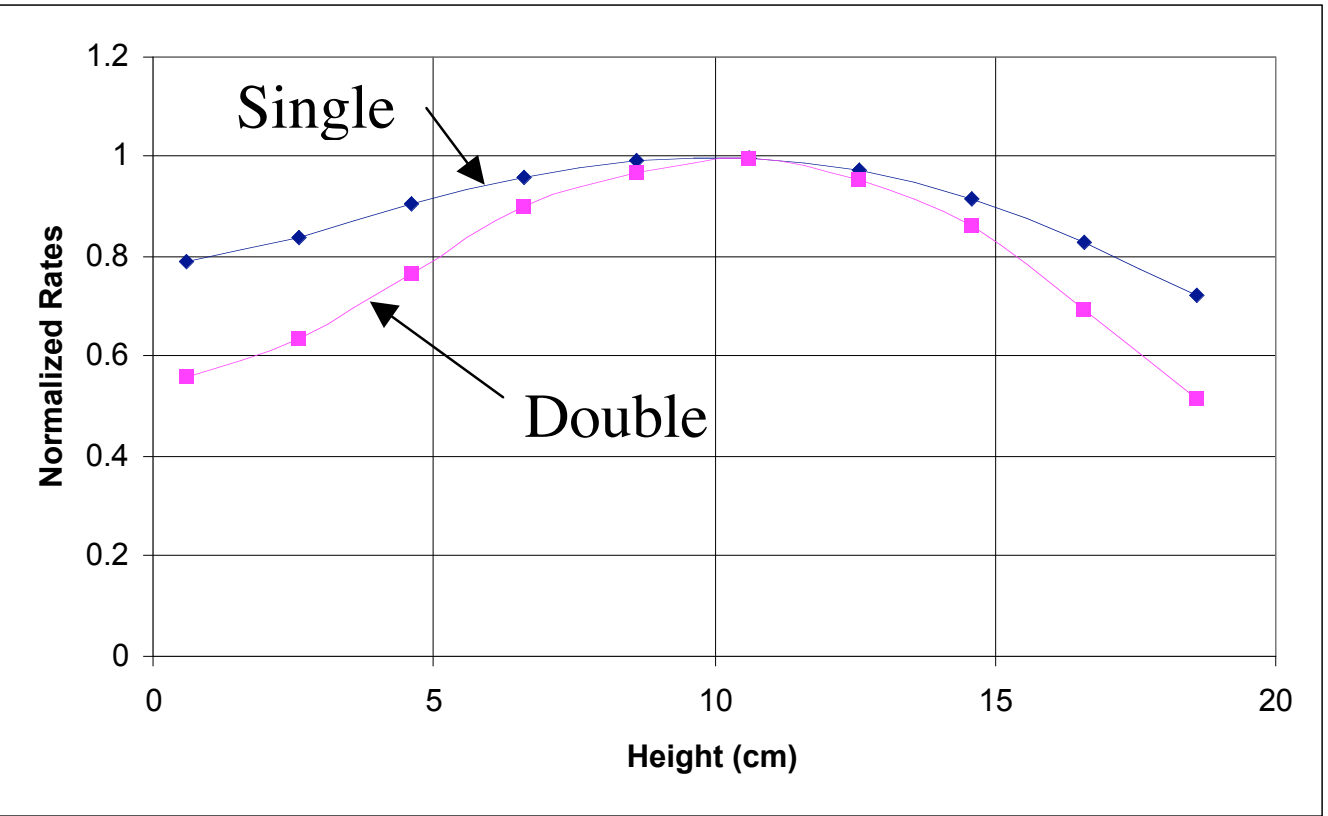

Fig. 13. Vertical efficiency profile for a point source in the PHNC with 2 slabs.

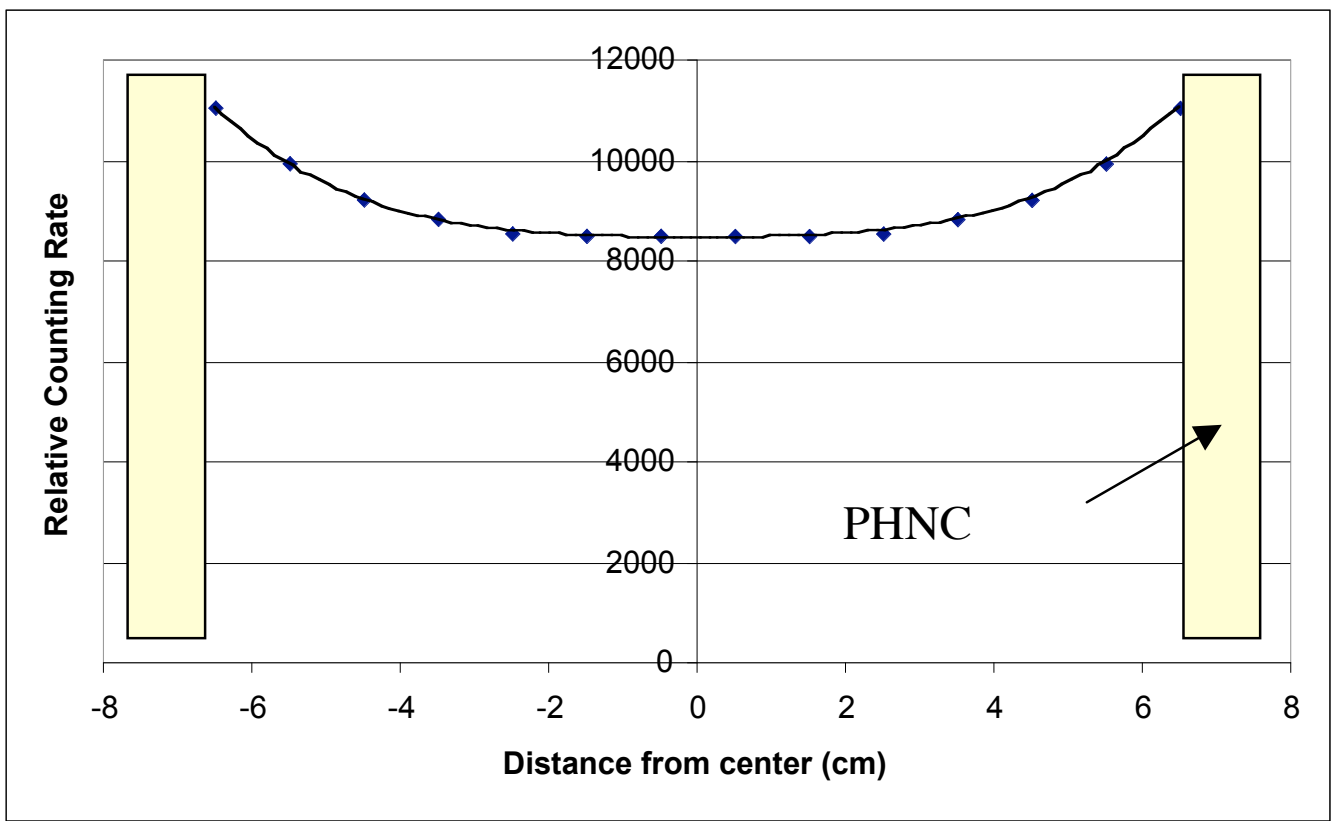

Fig. 14. Detector face response profile for a Cf-252 source in the PHNC with 2 slabs. 


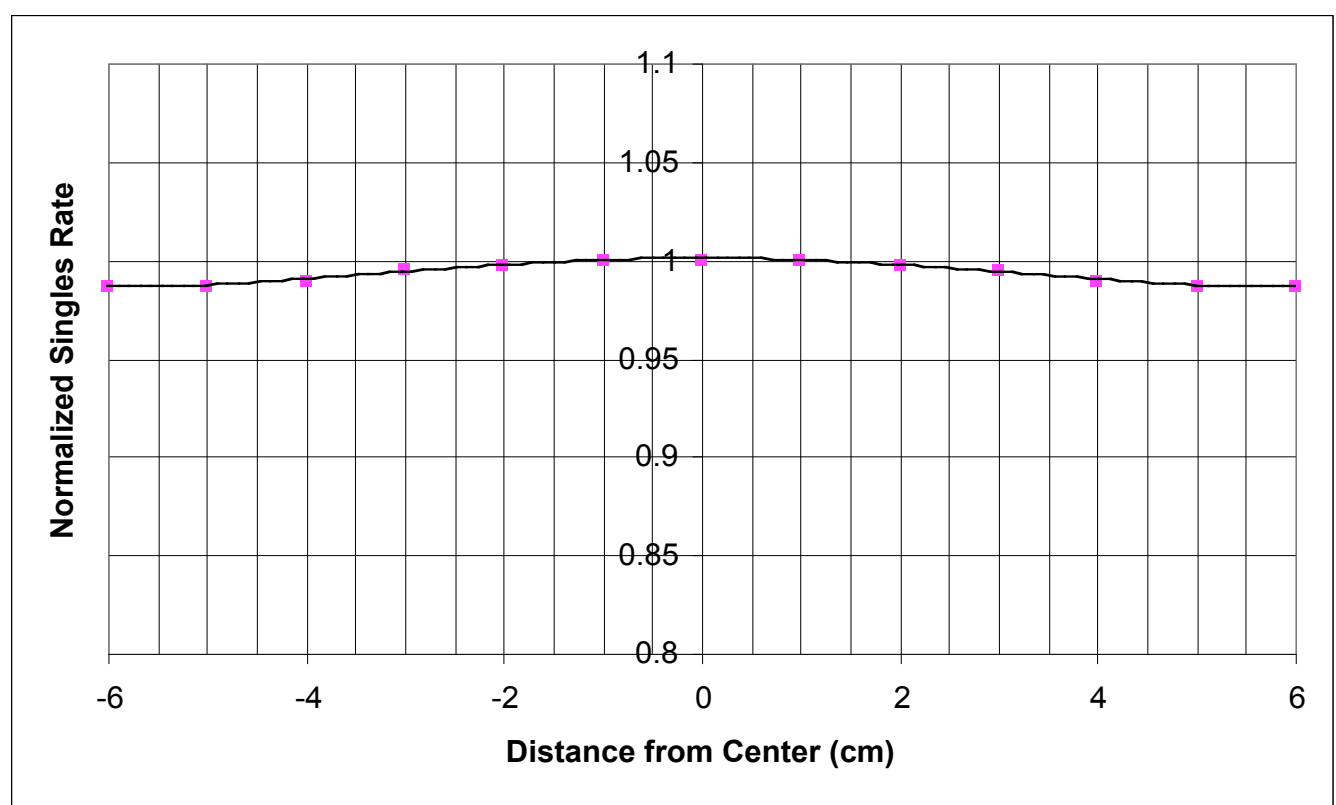

Fig. 15. Detector side response profile for a Cf-252 source in the PHNC.

\section{G. Stability and Moisture Sensitivity}

The stability of the PHNC was tested by repetitively counting a Cf-252 source for 93 cycles of $600 \mathrm{~s}$ each. The measured stability was $0.041 \%$ in the doubles rate over the $15-\mathrm{h}$ period. In general, the stability of the system is much better than the expected statistical precision in the measured doubles rates.

The PHNC has the HV components potted in silicone to insulate the system from humidityinduced HV breakdown. Humidity sensitivity tests were performed by placing the PHNC in a chamber with $100 \%$ relative humidity for five days and measuring the low-level background rate. The measured background rate remained the same as for the dry tests at $0.071 \mathrm{cps}$ during the 5-day test period. There is no desiccant required for the PHNC detectors.

\section{H. Vibration Tests}

For field use of the PHNC in the search mode, we expect to take data while in motion, with the associated vibrations. In general, He-3 tube based neutron counters are insensitive to motion and vibration. To test the PHNC for vibration sensitivity, we exposed a PHNC slab to repeated shocks and vibrations that were larger than what would be expected from the carrying case being pulled over gravel or rough concrete. The results of the tests are displayed in Fig. 16, where the average background rate was 0.071 for stationary conditions and 0.072 for vibration conditions. 


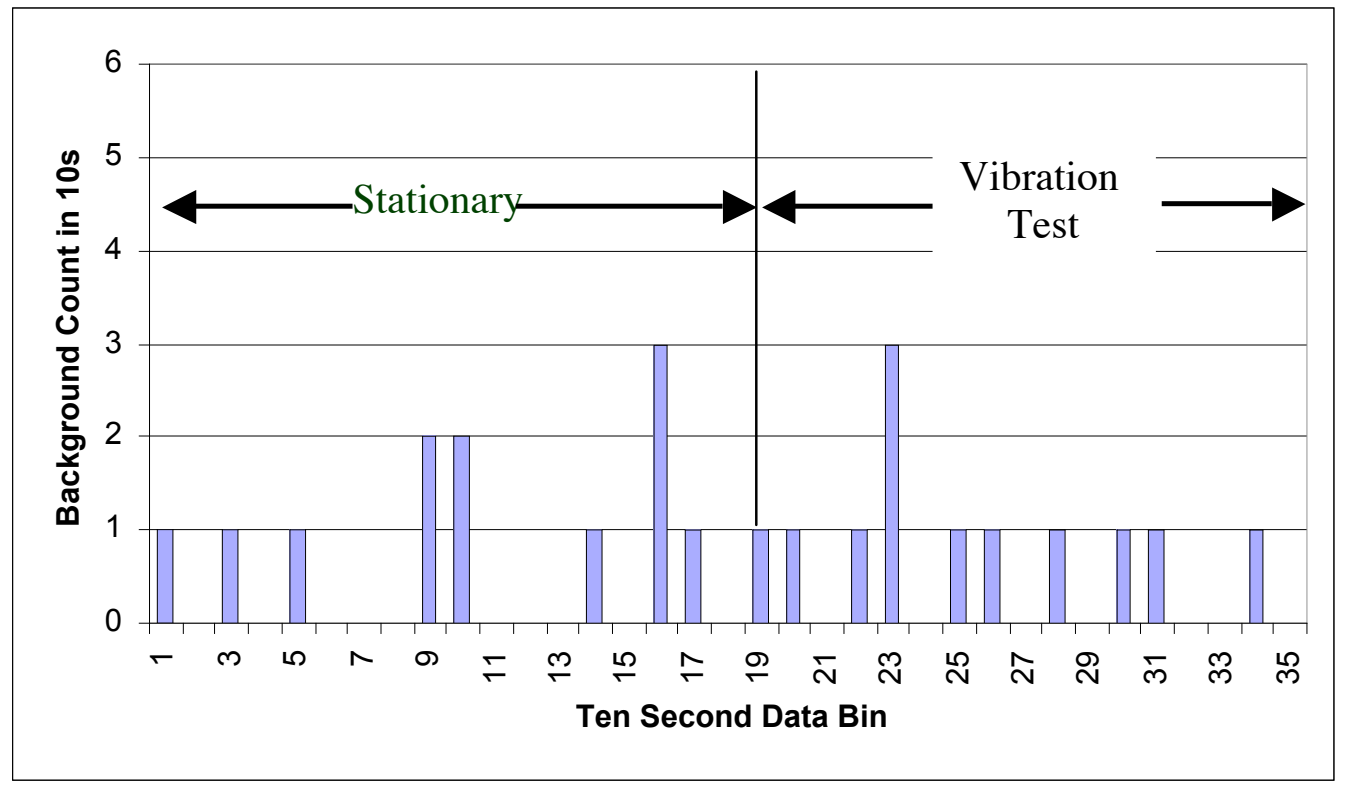

Fig. 16. PHNC vibration tests results.

\section{PHNC 2-SLAB CALIBRATION}

The 7 PHNC units were matched to have the same efficiency with an RSD of $0.5 \%$, as shown in Table I. The primary purpose of matching the efficiencies of all of the PHNC units is so they can be used interchangeably, and only a single calibration is required for all of the units. For quantitative coincidence counting, the sample/detector configuration will require a specific calibration, but it will be independent of the particular PHNC modules that were used.

Table VI lists standards that were used for the PHNC calibration. These standards include separated $\mathrm{Pu}-240$ to minimize any neutron multiplication.

TABLE VI. LANL Standards for the PHNC Calibration

\begin{tabular}{|c|c|c|c|c|c|c|}
\hline Standard ID & Material & Multiplicity Alpha & $\begin{array}{c}\text { Total } \\
\mathrm{Pu}(\mathrm{g})\end{array}$ & $\begin{array}{c}\text { Isotopics } \\
\text { Date }\end{array}$ & Pu-239 $(\mathrm{g})$ & $\begin{array}{c}\text { Pu-240 } \\
(\mathrm{g}) 9 / 15 / 05\end{array}$ \\
\hline & & & & & & \\
\hline FZC-158 & $\mathrm{Pu}-240$ oxide & Low (0.169) & 0.695 & $78 / 12 / 15$ & 0.006 & 0.695 \\
\hline & & & & & & \\
\hline P240 & Pu-240 oxide & Low (0.184) & 55.57 & $02 / 12 / 04$ & 3.22 & 52.2 \\
\hline & & & & & & \\
\hline $646078+081$ & MOX pellets & Medium (1.08) & 1.314 & $91 / 08 / 30$ & 1.1620 & 0.145 \\
\hline
\end{tabular}


The calibration procedure is to measure the standards listed in Table VI and do a best fit of the results to determine the PHNC efficiency, doubles, and triples gate fractions. The calibration of the PHNC is dependent on the geometric configuration of the detector slabs and HDPE reflectors, so the calibration constant needs to be determined for the specific conditions. Because the top of the 2-slab configuration is open, the neutron leakage through the top will change for different sample packages.

The standards isotopic vectors are listed in Table VII. Table VIII gives the results of the calibration measurement, and Fig. 17 shows a plot of the $\mathrm{D}$ as a function of the ${ }^{240} \mathrm{Pu}$ effective mass, where

$$
{ }^{240} \mathrm{Pu}_{\text {eff }}=2.52{ }^{238} \mathrm{Pu}+{ }^{240} \mathrm{Pu}+1.68{ }^{242} \mathrm{Pu} \text {. }
$$

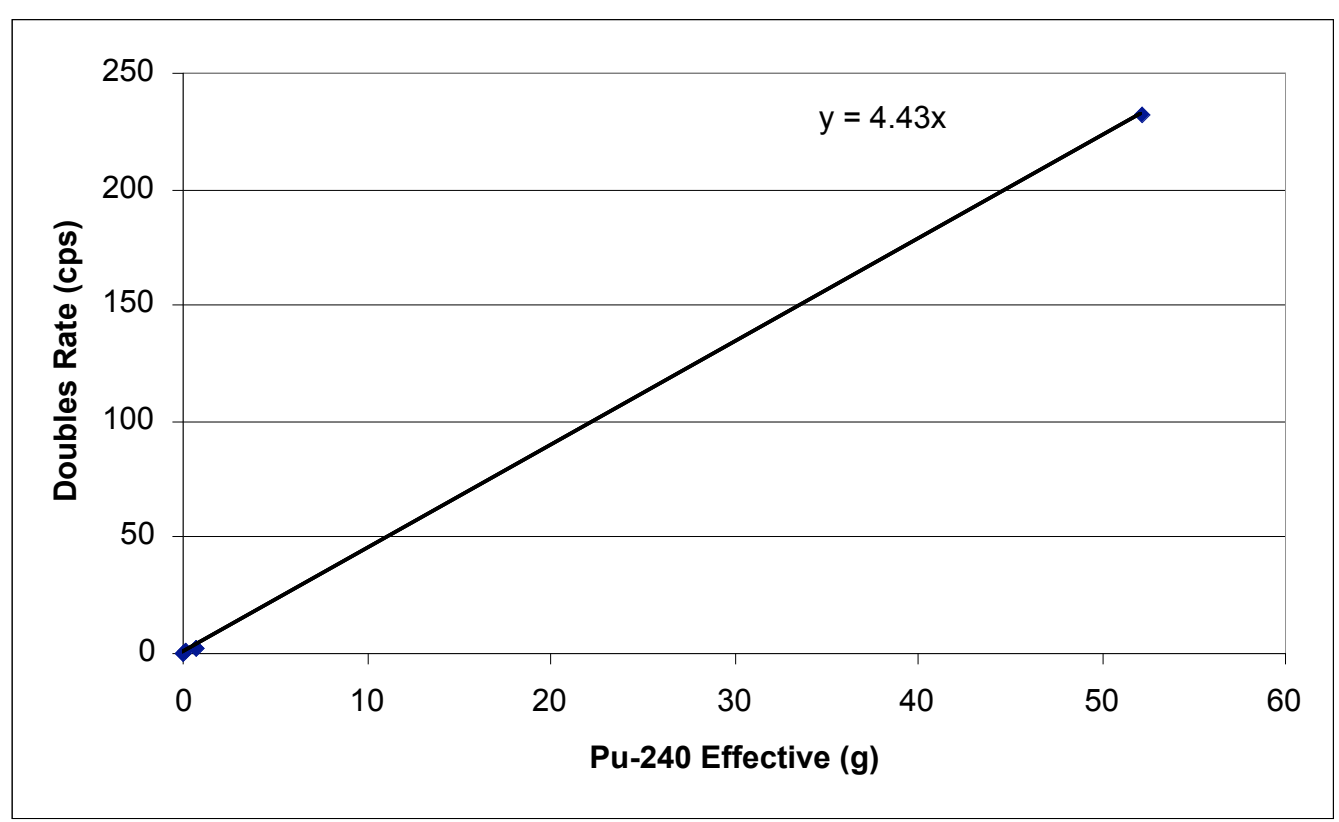

Fig. 17. Calibration response line (D) for small $\mathrm{PuO}_{2}$ and $\mathrm{MOX}$ standards. 


\begin{tabular}{|c|c|c|c|c|c|c|c|c|c|c|c|c|}
\hline & & \multicolumn{6}{|c|}{ Pellet date August 30, 1991} & & & & & \\
\hline & & \multicolumn{6}{|c|}{$\mathrm{Wt} \%$ (relative to total plutonium mass) } & & & & & \\
\hline ID & $\mathrm{gPu}$ & ${ }^{238} \mathrm{Pu}$ & ${ }^{239} \mathrm{Pu}$ & ${ }^{240} \mathrm{Pu}$ & ${ }^{241} \mathrm{Pu}$ & ${ }^{242} \mathrm{Pu}$ & ${ }^{241} \mathrm{Am}$ & $\mathrm{g}^{239} \mathrm{Pu}{ }_{\text {-eff }}$ & $\mathrm{g}^{240} \mathrm{Pu}{ }_{- \text {eff }}$ & $\begin{array}{c}\text { Known } \\
\text { Alpha }\end{array}$ & \begin{tabular}{c|} 
MOX \\
Ratio U/Pu \\
\end{tabular} & $\begin{array}{c}\text { Enrich } \\
(\%)\end{array}$ \\
\hline 646081 & 0.5077 & 0.0856 & 88.4296 & 10.3053 & 0.8844 & 0.2951 & 0.2443 & 1.2561 & 0.0559 & 0.673 & 17.5092 & 0.7400 \\
\hline 646078 & 0.8061 & 0.0856 & 88.4296 & 10.3053 & 0.8844 & 0.2951 & 0.2443 & 1.4778 & 0.0888 & 0.674 & 10.0922 & 0.7400 \\
\hline & & \multicolumn{7}{|c|}{$\mathrm{PuO}_{2}$} & & & & \\
\hline & & \multicolumn{6}{|c|}{$\mathrm{Wt} \%$ (relative to total plutonium mass) } & Date & & & & \\
\hline FCZ-158 & 0.695 & 0.016 & 0.955 & 93.77 & 0.699 & 4.56 & 0.001 & 1978-12-15 & 0.705 & 0.142 & & \\
\hline $\mathrm{P} 240$ & 55.57 & 0.0025 & 5.8014 & \begin{tabular}{|l|}
94.1396 \\
\end{tabular} & 0.0565 & N/A & 0.4145 & 2002-12-04 & 52.2 & 0.153 & & \\
\hline
\end{tabular}

\begin{tabular}{|c|c|c|c|c|c|c|c|}
\hline Sample & $\begin{array}{l}{ }^{240} \mathrm{Pu}_{\text {-eff }} \\
(\mathrm{g})\end{array}$ & $\begin{array}{l}\text { Time } \\
(\mathrm{s})\end{array}$ & $\begin{array}{c}\mathrm{S} \\
\text { (counts/s) }\end{array}$ & $\begin{array}{c}\mathrm{D} \\
\text { (counts/s) }\end{array}$ & $\begin{array}{c}\mathrm{T} \\
\text { (counts/s) }\end{array}$ & $\begin{array}{c}\mathrm{D}_{\mathrm{mc}} \\
\text { (counts/s) }\end{array}$ & $\begin{array}{c}\mathrm{D}_{\mathrm{mc}} / \mathrm{g} \\
{ }^{240} \mathrm{Pu}_{\mathrm{eff}}\end{array}$ \\
\hline FZC-158 & 0.695 & $74 \times 100$ & -- & $2.75 \pm 0.02$ & $0.083 \pm 0.007$ & $2.75 \pm 0.02$ & 3.96 \\
\hline FZC-158 & 0.695 & $218 \times 100$ & 61.02 & $2.77 \pm 0.02$ & $0.080 \pm 0.007$ & $2.77 \pm 0.02$ & 3.99 \\
\hline P240 & 52.2 & $117 \times 100$ & 5323 & $307.3 \pm 0.69$ & $16.70 \pm 0.443$ & $232.6 \pm 0.69$ & 4.45 \\
\hline $646078+646081$ & 0.145 & $88 \times 100$ & 22.38 & $0.664 \pm 0.01$ & $0.023 \pm 0.002$ & 0.664 & 4.59 \\
\hline & & & & & & Average & 4.34 \\
\hline
\end{tabular}


The spread in the doubles calibration slope $(3.98-4.59 \mathrm{cps} / \mathrm{g} \mathrm{Pu}-240)$ is probably caused by the different types of containment used for the three standards. The loss of efficiency from neutron leakage through the top of the 2-slab PHNC is a function of the multi-layered cans that surround the plutonium. We will use the average calibration slope of $4.34 \mathrm{cps} / \mathrm{g} \mathrm{Pu}-240$. For field use, the results will be impacted by the container size and shape.

The multiplicity calibration is determined from a best fit of the standard samples. The 2slab efficiency was determined to be $7.40 \%$, and the doubles gate and triples gate were adjusted to provide a best fit to the standards when measured in the multiplicity mode. The Known Alpha method shows large errors for the impure samples that have incorrect alpha values, based on the calculation from the isotopic vectors.

Once the detection system is characterized and calibrated for the standard configuration, measurements that are taken in any nonstandard configuration can be normalized to the standard configuration, using the MCNPX model.

\section{DETECTABILIY LIMIT}

\section{A. Room Background}

The background in the PHNC comes from both cosmic-ray spallation and the storage of neutron sources and plutonium in adjacent areas. The cosmic-ray spallation is the only significant source of $\mathrm{D}$ and $\mathrm{T}$ neutrons where the spallation events take place inside the detector body and shield and the sample. Many of these coincidence events are eliminated in the INCC [6] software by means of their large multiplicity.

The room backgrounds were measured at Los Alamos and are listed in Table IX. The backgrounds at sea level are expected to be about a factor of 6 less than at LANL on the surface because of the reduced cosmic ray activity at sea level.

\begin{tabular}{|c|c|c|c|}
\hline \multicolumn{4}{|c|}{ TABLE IX. Room Neutron Backgrounds for 2-Slab Configuration } \\
\hline Location & $\begin{array}{c}\text { Time } \\
(\mathrm{s})\end{array}$ & $\begin{array}{c}\text { S } \\
\text { cps }\end{array}$ & $\begin{array}{c}\mathrm{D} \\
\text { cps }\end{array}$ \\
\hline $\begin{array}{c}\text { LANL, TA-35, } \\
\text { Bldg. 27, surface }\end{array}$ & $20 \times 100$ & 8.0 & 0.006 \\
\hline $\begin{array}{c}\text { LANL, TA-35, } \\
\text { Bldg. 27, 3 }\end{array}$ & $50 \times 900$ & 0.136 & 0.000 \\
\hline $\begin{array}{c}\text { Sea Level } \\
\text { (estimate) }\end{array}$ & N/A & 1.6 & 0.001 \\
\hline
\end{tabular}

If the PHNC were used in a facility that had plutonium storage, the singles rate would be expected to increase significantly, depending on local neutron shielding. However, the doubles rate would not increase. 


\section{B. Lower Limit of Detection (LLD)}

There is interest in determining the LLD for a sample in the center of the 2-slab PHNC. For example, the LLD at a facility can be estimated from the equation

$\operatorname{LLD}=(1.3)(3) \operatorname{SQRT}[(\mathrm{D}+\mathrm{A}) / \mathrm{t}+\mathrm{a}(\mathrm{LLD}) / \mathrm{t}] / \mathrm{a}$,

where $\mathrm{a}=$ doubles calibration slope $(4.34 \mathrm{cps} / \mathrm{g} 240)$,

$\mathrm{t}=$ measurement time (assume $1000 \mathrm{~s}$ ),

$\mathrm{D}=$ doubles background rate $(0.001 \mathrm{cps})$,

$\mathrm{S}=$ singles background (assume $5 \mathrm{cps}$ ), and

$\mathrm{A}=$ accidental rate $(0.003 \mathrm{cps})$.

The LLD equation is a 3 sigma of the background LLD definition, where the 1.3 is a coincidence correlation factor. We assume that the background rate D is measured for a time interval that is much larger than the sample measurement time $t$.

Solving the LLD equation gives

$$
\mathrm{LLD}=4.1 \mathrm{mg} \mathrm{Pu}-240 \text { or } \sim 68 \mathrm{mg} \mathrm{Pu} \text { for } 6 \% \mathrm{Pu} 240 \text {. }
$$

For normal bulk sample measurements, the room background $\mathrm{S}$ is small, and the background measurement prior to the sample measurement is adequate. For low mass samples that approach the LLD, it is best to use the measured doubles rate and subtract the room $\mathrm{D}$, which is relatively constant.

\section{APPLICATIONS}

\section{A. Wide-Area Search Mode}

The primary application of the PHNC is for locating neutron sources in the search mode. The PHNC can be configured with two slabs in a rolling carrying case (Fig. 18) or with one slab in the shoulder carrying case. The search mode uses totals neutron counting for short intervals that can be set from 1 to $600 \mathrm{~s}$. 


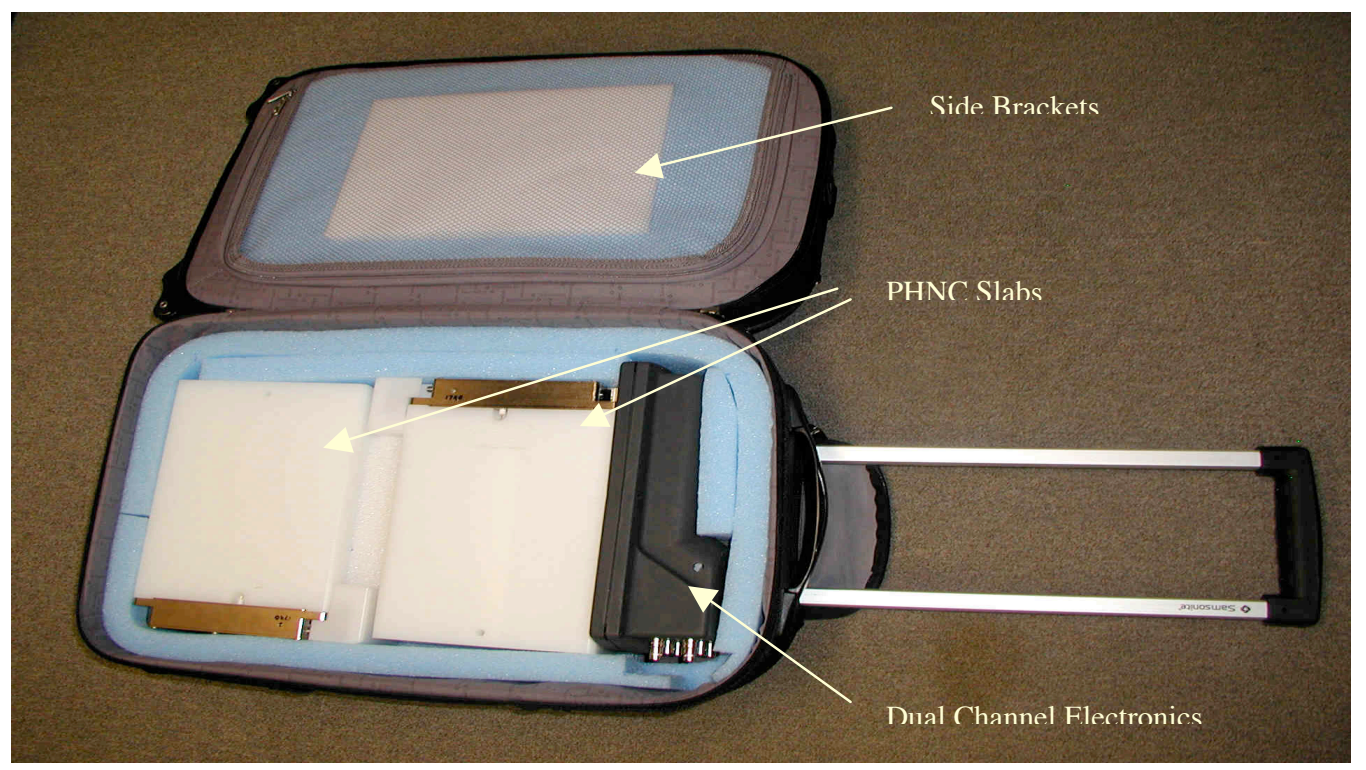

Fig. 18. The carrying case for 2-slab PHNC and dual-channel veto electronics.

Measurements were made for the neutron singles count rate as a function of the separation distance between the PHNC and the source. Figure 19 shows the counting rate for a Cf-252 source (Cf-9, yield of 61800n/s) versus distance from the face of 2 slabs in the suitcase shown in Fig. 18. The side brackets and bottom plate were in the carrying case during the measurements. These components increase the counting efficiency for an external source. The comparison data for the low background counter (LBC) are presented in Fig. 19, showing that the LBC is a factor of 2.5 more efficient for measuring a distant source. This is a result of the larger size and weight of the LBC [7].

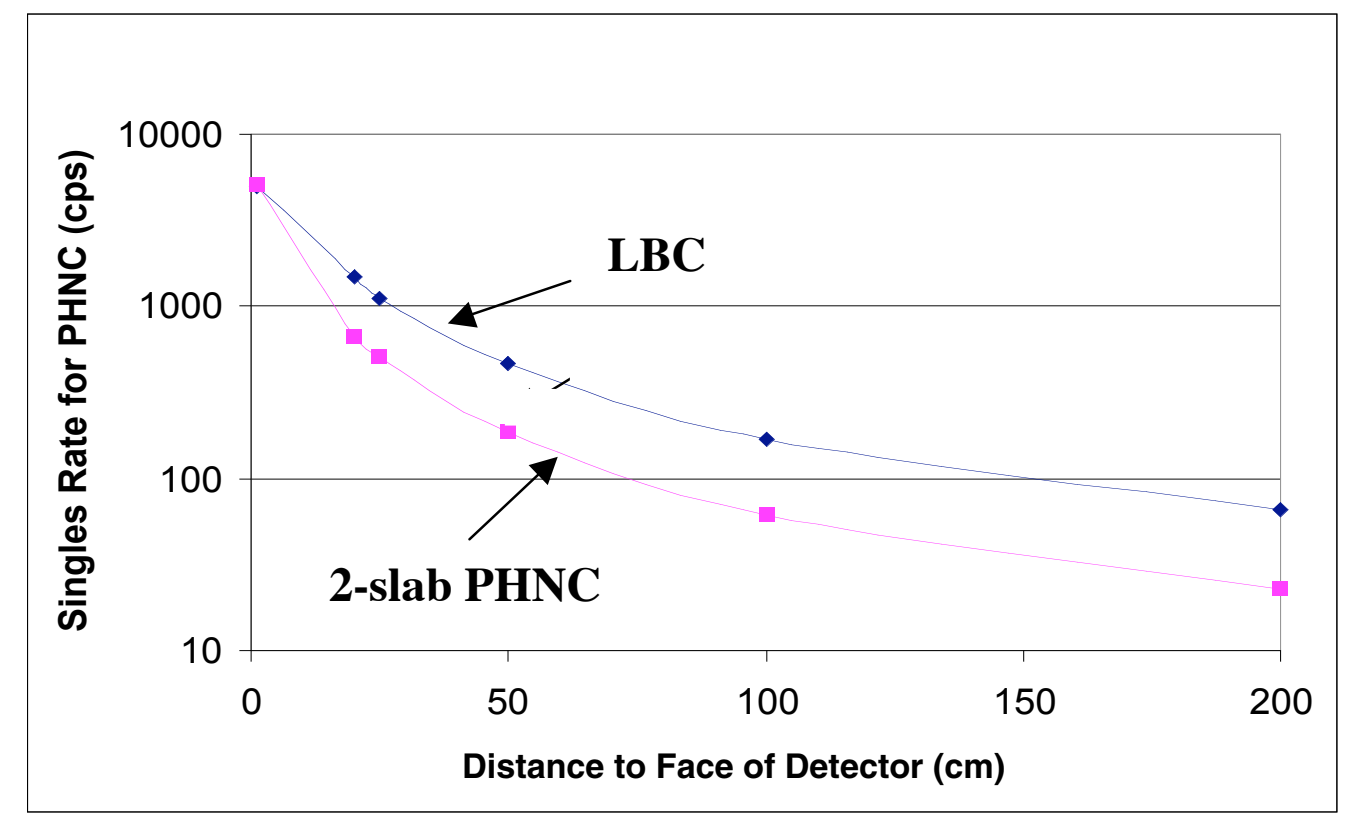

Fig. 19. Singles rate for Cf-9 $(62500 \mathrm{n} / \mathrm{s})$ as a function of distance from the face of the 2-slab PHNC and the LBC. 


\section{B. Quantitative Coincidence Mode}

For storage facilities that have containers of plutonium metal or oxides, the PHNC is configured in the 2-slab or 4-slab mode to measure the Pu-240 neutrons in the coincidence mode. The sample plutonium mass can range from less than a gram to hundreds of grams. The containers can be stainless steel, Al, or glass, with or without plastic bagging. The sample sits on top of an $90 \mathrm{~mm}$ tall metal mini-jack in the bottom of the sample cavity. The mini-jack should be adjusted to position the center of the plutonium mass in the center of the counter. Each container type will require a unique calibration.

Typical measurement times are 10-15 min for the coincidence doubles measurements to obtain a statistical precision of $\sim 2-3 \%$ for pure oxide samples. The uncertainty will be much larger for impure sample that will require multiplicity counting. A multiplicity mode measurement for an impure oxide sample would require more than an hour because of the low efficiency in the PHNC.

\section{SUMMARY}

A new portable handheld neutron counter, the PHNC, has been developed for fieldconfigurable use in conditions where a flexible neutron detector is needed. The PHNC consists of a pair of ${ }^{3} \mathrm{He}$ detector slabs housed in a carrying case and controlled by battery operated electronics and a microcomputer. Multiple detectors can be operated as a single detection system. The PHNC is applicable for large area surveys and for source location and identification, as well as for quantitative assay. A MCNPX model of the detectors in a standard configuration has been assembled and enables normalization of data taken in a nonstandard configuration.

Singles neutron counting is used for the search mode and for coincidence counting of the $\mathrm{Pu}-240$ that is used for the quantitative assay. In the search mode, the most important performance parameter, the effective surface area (ESA), is the intrinsic efficiency (13.3\%) times the surface area $\left(903 \mathrm{~cm}^{2}\right)$ in the direction of the neutron source. For the detector configuration shown in Fig. 18, the ESA is 120-cps/unit neutron flux.

The tests related to noise from high humidity and vibration showed that the PHNC detectors are free of the problem, so data can be taken while the units are in motion. No desiccant is required for the PHNC.

In the coincidence mode, the PHNC can measure a small sample to a counting precision of $2-4 \%$ in 10-15 min. The accuracy will be much worse than the precision because of calibration errors and the effect of multiplication from the unknown alpha source neutrons. The multiplicity mode application would require an order of magnitude increase in the measurement time. 
The LLD for the PHNC is low because of the small size and low background. Using the doubles counting rate, the LLD is $\sim 68 \mathrm{mg}$ of plutonium $\left(6 \%{ }^{240} \mathrm{Pu}\right)$.

Calibration of the PHNC in a variety of configurations, including the standard one, will be accomplished in the near term. Those data will be compared with the results of the MCNPX model for benchmarking the field-configurable assay approach.

\section{REFERENCES}

1. H. O. Menlove, "The Role of Neutrons in Safeguards," JNMM XV (4) 83-87, Los Alamos National Laboratory document LA-UR-87-1401 (July 1987).

2. M. C. Miller, H. O. Menlove, A. L. Thornton, C. D. Rael, and L. K. Fulton, "A Portable Neutron Counter for Field Surveys and Assay," $27^{\text {th }}$ ESARDA Symposium on Safeguards and Nucl. Mater. Manage., May 10-12, 2005. Los Alamos National Laboratory document LA-UR-05-3492.

3. Precision Data Technology, Inc., $60140^{\text {th }}$ Place, Everett, WA 98201.

4. M. R. Newell and D. C. Jones, "Dual Counter With Veto User Manual," Los Alamos National Laboratory document LA-UR-05-7428.

5. M. R. Newell, Private communication on the status of the Hand-Held Multiplicity Register (HMMR), September 2005.

6. W. C. Harker and M. S. Krick, "INCC Software User's Manual," Los Alamos National Laboratory report LA-UR-01-6761 (November 2001).

7. M. T. Swinhoe, Private communication on the Low Background Counter, September 2005. 
This report has been reproduced directly from the best available copy. It is available electronically on the Web (http://www.doe.gov/bridge).

Copies are available for sale to U.S. Department of Energy employees and contractors from:

Office of Scientific and Technical Information P.O. Box 62

Oak Ridge, TN 37831

(865) 576-8401

Copies are available for sale to the public from: National Technical Information Service

U.S. Department of Commerce

5285 Port Royal Road

Springfield, VA 22161

(800) 553-6847 
Los Alamos NATIONAL LABORATORY EST. 1943 